\title{
Smoking-Related Attitudes and Knowledge Among Medical Students and Recent Graduates in Argentina: A Cross-Sectional Study
}

\author{
M. Victoria Salgado, $M D^{1,2}$, Raúl M. Mejía, MD, PhD², Celia P. Kaplan, DrPH, $M A^{3}$, and \\ Eliseo J. Pérez-Stable, $M D^{3,4}$
}

\begin{abstract}
'Facultad de Medicina, Universidad de Buenos Aires, Buenos Aires, Argentina; ${ }^{2}$ Centro de Estudios de Estado y Sociedad, Buenos Aires, Argentina; ${ }^{3}$ Division of General Internal Medicine, Medical Effectiveness Research Center for Diverse Populations, Department of Medicine, Helen Diller Family Comprehensive Cancer Center, University of California San Francisco, San Francisco, CA, USA; ${ }^{4}$ National Institute on Minority Health and Health Disparities, National Institutes of Health, Bethesda, MD, USA.
\end{abstract}

\begin{abstract}
BACKGROUND: Physicians in Argentina smoke at rates similar to the general population, and do not have a clear role in tobacco control strategies.

OBJECTIVE: To describe the attitudes and knowledge of medical students and recent graduates towards smoking behavior in Argentina.
\end{abstract}

DESIGN: Cross-sectional self-administered online survey conducted in 2011.

PARTICIPANTS: Medical students and recent medical graduates from the University of Buenos Aires.

MAIN MEASURES: Attitudes and knowledge were evaluated by responses to 16 statements regarding the effects of smoking cigarettes and the role of physicians in tobacco control. Rates of agreement with a full ban on indoor smoking in different public settings were assessed.

KEY RESULTS: The sample included 1659 participants (response rate: $35.1 \%$ ), 453 of whom (27.3\%) were current smokers. Only $52 \%$ of participants agreed that doctors should set an example for their patients by not smoking, $30.9 \%$ thought that medical advice had little effect on patients' cessation behavior, and $19.4 \%$ believed that physicians could decline to care for smoking patients who failed to quit. In adjusted logistic regression models, current smokers had less supportive attitudes about tobacco control and were less likely than non-smokers to agree with a full indoor smoking ban in hospitals (OR: 0.30; $95 \%$ CI 0.16-0.58), universities (OR: 0.55; $95 \%$ CI 0.41-0.73), workplaces (OR: 0.67; $95 \%$ CI 0.50-0.88), restaurants (OR: 0.42; $95 \%$ CI 0.33-0.53), cafes (OR: $0.41 ; 95 \%$ CI 0.33-0.51), nightclubs (OR: 0.32; $95 \% \mathrm{CI}$ 0.25-0.40), and bars (0.35; $95 \%$ CI 0.28-0.45). Recent medical graduates had more accurate knowledge about cessation and were more likely to agree with a full smoking ban in recreational venues.

CONCLUSIONS: Although most participants reported a strong anti-tobacco attitude, a proportion still failed to recognize the importance of their role as physicians in tobacco control strategies. Current smokers and current

Electronic supplementary material The online version of this article (doi:10.1007/s11606-016-3890-0) contains supplementary material, which is available to authorized users.

Received April 26, 2016

Revised July 22, 2016

Accepted September 14, 2016

Published online October 11, 2016 students were less likely to support indoor smoking bans. Specific educational curricula could address these factors.

KEY WORDS: smoking; medical students; attitudes; Latin America. $\mathrm{J}$ Gen Intern Med 32(5):549-55

DOI: $10.1007 / \mathrm{s} 11606-016-3890-0$

(c) Society of General Internal Medicine 2016

\section{INTRODUCTION}

Physicians play an important role in tobacco control by offering a point-of-care cessation counseling option, although studies have found that they often do not assess their patients' smoking status, provide only limited advice, and do not offer cessation treatment as regularly as they should. ${ }^{1-4}$ However, physicians not only have the potential to help their patients quit smoking; they are also considered "role models." $5 \mathrm{Al}-$ though training physicians on tobacco cessation improves their adherence to smoking treatment guidelines, their counseling performance may ultimately have little impact on the smoking status of their patients. ${ }^{6-10}$ Moreover, while positive attitudes towards cessation advice appear to be correlated with greater odds of providing such advice, ${ }^{11}$ physicians' perceptions of the effectiveness of and recommendation of cessation counseling may be negatively affected by their personal smoking status. ${ }^{12,} 13$ Therefore, the study of health professionals' attitudes towards smoking and tobacco control offers an opportunity for analyses that may result in new strategies focused mainly on providing training. ${ }^{14}$

Considering that medical students are "soon to be" physicians, their smoking behavior and attitudes have been the object of multiple studies around the world. ${ }^{15-21}$ Smoking prevalence among physicians has declined in most highincome countries, but it remains highly variable in middleincome countries, ${ }^{2-24}$ including among medical students. ${ }^{25}$ Smoking prevalence among US students in the health profession is close to $7 \%{ }^{26}$ In Europe, it ranges from $3.8 \%$ in Wales $^{27}$ to $22.1 \%$ in Germany ${ }^{28}$; in Asia, from $2.1 \%$ in Thailand $^{29}$ to $66.9 \%$ among Chinese men. ${ }^{30}$ Among Latin American countries, it was estimated that $16.9 \%$ of Brazilian 
medical students were current smokers, while this proportion was reported to be $41.1 \%$ in Bolivia. ${ }^{29}$

Argentina is a high-middle-income South American country with a smoking rate of $22.1 \%{ }^{31}$ Previous research has shown that rates of smoking among medical students in Argentina are at least as high as those in the general population. $^{19,} 32,33$ The School of Medicine at the University of Buenos Aires (UBA) is the largest in the country; students enroll after graduating from high school, with completion in about 7 years. ${ }^{34}$ A previous survey conducted among its medical students found that more than $90 \%$ thought that health professionals should receive specific training on smoking cessation techniques, but less than $10 \%$ reported having any training in medical school. ${ }^{33}$ Although this survey partially addressed UBA medical students' attitudes and knowledge about tobacco, these topics are in need of further exploration. Studies have shown that media images of smoking, particularly in movies, are linked to smoking and smoking initiation among adolescents. ${ }^{35-40}$ Therefore, media literacy - or the ability to analyze and evaluate media messages ${ }^{41}$ - has been proposed as a tool to better interpret media messages related to smoking, potentially influencing attitudes towards smoking and smoking behavior. Prior studies have shown an association between the level of smoking media literacy and smoking status among adolescents in the USA and in Jujuy, Argentina, as well as in US college students. ${ }^{42-44}$ In a previous article, we analyzed access to tobacco company websites among medical students from UBA. ${ }^{45}$ The objective of the present paper is to describe the attitudes and knowledge of these medical students and recent graduates towards smoking and smoking behavior, including their level of smoking media literacy, based on their smoking status.

\section{METHODS}

\section{Study Procedures}

In 2011, current and former UBA medical students were invited through email communication to participate in a onetime self-administered online survey. Email addresses were obtained from the registry of the required 1-year rotating internship (the last practice-based year of medical school before graduation), the pharmacology department of the UBA School of Medicine, and the main university teaching hospital. Datstat Illume software was used to conduct the survey. ${ }^{46}$ Over the course of 11 weeks, one initial email and 14 reminder messages were sent requesting participation. The links allowing access to the questionnaire were disabled after the last email resulted in no new responses. Inclusion criteria were age of 18-30 years, responding to smoking status questions, and status as current or recent medical student at UBA School of Medicine. The institutional review committee of the Hospital de Clínicas, UBA, approved the study protocol. A more detailed description of data collection methods as well as the instrument development was described previously. ${ }^{45}$

\section{Smoking Behavior Variables}

The questionnaire included questions regarding participants' demographic characteristics, cigarette consumption, tobacco dependence, knowledge about tobacco and tobacco cessation, attitudes towards smoking, and smoking media literacy. A participant was considered a current smoker if he/she reported to have smoked a cigarette in the 30 days prior to the survey. A former smoker was someone who reported to have smoked cigarettes in the past but not within the previous 30 days. A never smoker had never tried a cigarette. Among current smokers, nicotine dependence was assessed using the Heaviness of Smoking Index, through two items of the Fagerström Test for Nicotine Dependence. Item 1 was time from waking to first cigarette, and item 4 was the number of cigarettes smoked per day (each score from 0 to 3). A participant was considered to have high nicotine dependence when the score was $\geq 4 .{ }^{47-49}$

\section{Attitudes and Knowledge About Tobacco Use}

Tobacco-related attitudes and knowledge were evaluated using a five-item Likert scale (from "strongly agree" to "strongly disagree") for 16 statements regarding the role of doctors in tobacco control, attitudes towards patients who smoked, effects of smoking, and effectiveness of counseling and smoking cessation treatment. ${ }^{9}$ Statements were adapted from a questionnaire used in a clinical study with Argentine physicians. ${ }^{9}$ Content validity was evaluated by cognitive interviews with ten UBA medical students. Factor analysis did not support acceptable psychometric properties for use as an attitudes and knowledge scale. Thus, the analysis was planned with individual items as outcomes.

The "agree" and "strongly agree" options and the "disagree" and "strongly disagree" options were combined into a single category ("agree" or "disagree"). The neutral option ("neither agree nor disagree") was differentially assigned to the response group that did not indicate an anti-smoking attitude or that did not correctly answer a knowledge question. For example, when the anti-smoking attitude or the correct knowledge answer implied "agreeing" with the statement, the neutral option was included among the "disagree" responses; when it implied "disagreeing" with the statement, the neutral option was included among the "agree" responses. Participants were also asked about their level of agreement with banning indoor smoking in various public places. ${ }^{9,} 33$ The questionnaire is in Online Appendix 1 in both Spanish and English.

\section{Smoking Media Literacy}

Smoking media literacy was assessed with a smoking media literacy (SML) scale, ${ }^{50}$ developed and used in the USA, and adapted for Argentine youth. ${ }^{42-44}$ The original scale has 18 
items divided into three domains: authors and audiences (AA), messages and meanings (MM), and representation and reality (RR). As a result of cognitive interviews conducted for transcultural adaptation, five items were deemed not relevant; therefore, the final version of the scale consisted of 13 of the 18 items. Items used included the following: "Tobacco companies are very powerful, even outside of the cigarette business." (AA); "When people make movies and TV shows, every camera shot is very carefully planned." (MM); and "Advertisements usually leave out a lot of important information." (RR). Each statement was evaluated using a four-point Likert scale, from "strongly disagree" (1 point) to "strongly agree" (4 points). Based on previous reports, high smoking media literacy was defined as an average score $\geq 3 .{ }^{43,}{ }^{44}$ After the survey was conducted, confirmatory factor analysis was used to verify adjustment to the original model. The complete list of all items used is available upon request.

\section{Data Analysis}

Data analysis was conducted using STATA software version 13 (StataCorp LP, College Station, TX, USA). Statistical significance was defined with a two-sided alpha of $0.05(P$ values $<0.05$ ). Descriptive analysis was used to compare respondents by sex. Chi-square tests were used for categorical variables. Logistic regression models were used to explore the association between the various attitude statements and opinions on banning indoor smoking and status as current smoker or recent graduate. Models using current smoking as outcome were designed to explore its association with the level of smoking media literacy (high or low). All models for both responses to attitudes, knowledge and full smoking ban, and SML were adjusted for age, gender, smoking status and student status.

\section{RESULTS}

Of the 4969 persons included in the database, 1743 (35.1\%) completed the survey, but 84 were excluded from analysis for not meeting the inclusion criteria. The final sample consisted of 1659 participants (33.4\% of the 4969 original); of these, $1212(73.1 \%)$ were women, $447(26.9 \%)$ were men and $55.7 \%$ were current medical students; 12 participants $(0.7 \%)$ reported to have dropped out of medical school before graduation. The majority of the recent medical graduates (605/ $723,83.7 \%$ ) had completed medical school in the 2 years prior to the survey (median: 2010; interquartile range: 1), and $99.2 \%$ of graduates had completed medical school in the 5 years prior to the survey. Table 1 presents the demographic and tobacco consumption characteristics. Among respondents, $453(27.3 \%)$ were current smokers at the time of the survey; $311(18.7 \%)$ were daily smokers. Almost all current smokers reported low nicotine dependence (434; $95.8 \%$ ). A more detailed description of the population and of current smokers' characteristics can be found in a previous publication. ${ }^{45}$
Table 1 Demographic Characteristics and Smoking Behavior Among 1659 Current Students and Recent Graduates, by Gender, at the University of Buenos Aires Medical School, Argentina, 2011

\begin{tabular}{llll}
\hline \hline & $\begin{array}{l}\text { Men } \\
(\boldsymbol{n}=\mathbf{4 4 7}) \\
\text { No. (\%) }\end{array}$ & $\begin{array}{l}\text { Women } \\
(\boldsymbol{n}=\mathbf{1 2 1 2}) \\
\text { No. (\%) }\end{array}$ & $\begin{array}{l}\text { Total } \\
(\boldsymbol{n}=\mathbf{1 6 5 9}) \\
\text { No. (\%) }\end{array}$ \\
\hline Age (years): & & & \\
$20-25$ & $131(29.3)$ & $372(30.7)$ & $503(30.3)$ \\
$26-27$ & $162(36.2)$ & $456(37.6)$ & $618(37.3)$ \\
$28-30$ & $154(34.5)$ & $384(31.7)$ & $538(32.4)$ \\
Student status: & & & \\
Currently enrolled student & $258(57.7)$ & $666(55.0)$ & $924(55.7)$ \\
Graduated as physician & $188(42.1)$ & $535(44.1)$ & $723(43.6)$ \\
$\begin{array}{l}\text { Dropped out of medical } \\
\text { school }\end{array}$ & $1(0.2)$ & $11(0.9)$ & $12(0.7)$ \\
Smoking status: & & & \\
$\quad$ Never smoker & $92(20.1)$ & $256(21.1)$ & $348(21.0)$ \\
$\quad \begin{array}{l}\text { Former smoker } \\
\text { Current smoker (total) }\end{array}$ & $225(50.3)$ & $633(52.2)$ & $858(51.7)$ \\
$\quad$ Current smoker (daily) & $89(29.1)$ & $323(26.7)$ & $453(27.3)$ \\
$\quad$ Current smoker (non- & $41(9.2)$ & $101(8.3)$ & $142(8.6)$ \\
daily) & & & \\
\hline
\end{tabular}

\section{Attitudes and Knowledge}

Table 2 presents the level of agreement with different statements regarding attitudes and basic tobacco control knowledge by smoking status. In addition, $84.6 \%$ of participants answered that medical students need more training on how to counsel patients on smoking cessation. Current smokers were significantly less likely than non-smokers to indicate a desire for more training $(79.9 \%$ vs. $86.4 \%$, respectively; $P<0.05$ ).

Recent medical graduates had more accurate knowledge about tobacco control strategies than did current medical students. These results are summarized in Online Appendix 2 (Table 2a).

Participants were also asked about their agreement with banning indoor smoking in various public places; Table 3 presents the results by smoking status. Overall, participants were less likely to agree with a full smoking ban in recreational venues, even though over $90 \%$ agreed with a ban in health care settings, schools and public transportation. In addition, current smokers were significantly even less inclined to agree with a full smoking ban in seven different sites. Current medical students were also less likely to agree with full smoking bans in recreational venues. Analysis by student status can be found in Online Appendix 2 (Table 3a).

\section{Multivariate Analysis}

Adjusted logistic regression models were used to assess the association between current smoker or recent medical graduate status and agreement with the attitudinal or knowledge statements and with a full smoking ban in public places. Table 4 presents the items in which a significant difference between current smokers and non-smokers was observed. Analyses by student status showed that recent graduates were significantly less likely to have selected smoking and cessation misconceptions and more likely to support a full smoking ban in recreational venues. 
Table 2 Knowledge and Attitudes Towards Smoking Among 1659 Current Students and Recent Graduates, by Smoking Status, University of Buenos Aires Medical School, Argentina, 2011

\begin{tabular}{|c|c|c|c|}
\hline \multirow[t]{2}{*}{ Attitudes } & \multirow{2}{*}{$\begin{array}{l}\begin{array}{l}\text { Total } \\
(n=1659)\end{array} \\
\text { Agree } \\
\text { No. }(\%)\end{array}$} & \multirow{2}{*}{$\begin{array}{l}\begin{array}{l}\text { Current smokers } \\
(n=453)\end{array} \\
\text { Agree } \\
\text { No. }(\%)\end{array}$} & \multirow{2}{*}{$\begin{array}{l}\text { Non-smokers } \\
(n=1206) \\
\text { Agree } \\
\text { No. }(\%)\end{array}$} \\
\hline & & & \\
\hline It is doctors' responsibility to help their patients quit smoking.* & $1412(85.1)$ & $371(81.9)$ & $1041(86.3)$ \\
\hline The physician has a responsibility not to smoke and set a good example for their patients* & $863(52.0)$ & $157(34.7)$ & $706(58.5)^{*}$ \\
\hline Regarding smoking cessation, medical advice has little effect on the behavior of patients. ${ }^{\dagger}$ & $512(30.9)$ & $142(31.4)$ & $370(30.7)$ \\
\hline $\begin{array}{l}\text { If a doctor wishes, he/she should be able to refuse to care for a patient just because he does not } \\
\text { quit smoking. }\end{array}$ & $322(19.4)$ & $61(13.5)$ & $261(21.6)^{\ddagger}$ \\
\hline It is useless to advise patients to quit smoking..$^{\dagger}$ & $142(8.6)$ & $38(8.4)$ & $104(8.6)$ \\
\hline $\begin{array}{l}\text { The consumption of tobacco is a matter of personal decision, in which the doctor should not } \\
\text { intervene. }\end{array}$ & $138(8.3)$ & $48(10.6)$ & $90(7.5) \S$ \\
\hline Patients already have too many problems to add to quit smoking. ${ }^{\dagger}$ & $73(4.4)$ & $25(5.5)$ & $48(4.0)$ \\
\hline Patients already know they should quit smoking It doesn't make sense to remind them of this. ${ }^{\dagger}$ & 95 (3.9) & $20(4.4)$ & $45(3.7)$ \\
\hline \multirow{2}{*}{\multicolumn{4}{|c|}{ 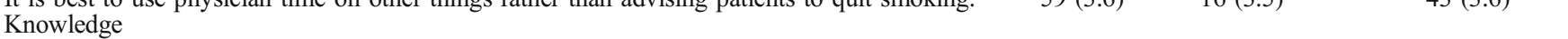 }} \\
\hline & & & \\
\hline Tobacco consumption is an addiction.* & $1590(95.8)$ & $424(93.6)$ & $1166(96.7)$ \\
\hline Of the patients who quit smoking, the majority succeed to do so on their first attempt. $\dagger$ & 325 (19.6) & $84(18.5)$ & $241(20.0)$ \\
\hline Smoking on non-daily basis is not harmful to health. $\dagger$ & $99(6.0)$ & $39(8.6)$ & $60(5.0)$ \\
\hline Tobacco smoke in the environment (passive smoking) is only harmful to young children. $\dagger$ & $63(3.8)$ & $19(4.2)$ & $44(3.7)$ \\
\hline Very light smoking ( $1-5$ cigarettes per day) is harmless to health. $\dagger$ & $51(3.1)$ & $23(5.1)$ & $28(2.3) \|$ \\
\hline $\begin{array}{l}\text { If a patient has smoked for a long time, it is too late to stop, because the patient won't be able } \\
\text { to do it. } \dagger\end{array}$ & $32(1.9)$ & $10(2.2)$ & $22(1.8)$ \\
\hline $\begin{array}{l}\text { If a patient has smoked for a long time, it is too late to stop, because their health is already } \\
\text { irreversibly affected. } \dagger\end{array}$ & $25(1.5)$ & $10(2.2)$ & $15(1.2)$ \\
\hline
\end{tabular}

Note: Non-smoker category includes never smokers and former smokers

"Statements in which the option "neither agree nor disagree" is included among the "disagree" responses

" Statements in which the option "neither agree nor disagree" is included among the "agree" responses

Non-smoker category includes never smokers and former smokers

Significant difference between current and non-smokers: ${ }^{\hbar} P<0.001,{ }^{\S} P=0.027 ; " ~ P=0.003$

Men were more likely than women to agree with the following statements: "Patients already have too many problems to add to quit smoking." (OR: 1.85, $95 \%$ CI 1.14-2.99, $P=$ 0.013); "If a patient has smoked for a long time, it is too late to stop, because the patient won't be able to do it." (OR: 2.57, $95 \%$ CI 1.26-5.22, $P=0.009)$; "It is best to use physician time on other things rather than advising patients to quit smoking." (OR: 3.17, $95 \%$ CI 1.86-5.41, $P<0.001$ ); and "If a doctor wishes, he/she should be able to refuse to care for a patient just because he does not quit smoking." (OR: 1.34, $95 \%$ CI 1.03-1.76, $P=0.031)$. No differences between genders were found when asked their opinions on banning smoking in public places.

\section{Smoking Media Literacy}

Most participants reported high SML scores (1458, 87.9\%). A statistically significant difference between current smokers and non-smokers was found only for the following individual items:

- "Tobacco companies are very powerful, even outside of the cigarette business." (total agreement: $87.2 \%$ vs. $98.8 \%$ respectively, $P=0.02$ )

- "There are often hidden messages in cigarette ads." (total agreement: $80.9 \%$ vs. $85.2 \%$ respectively, $P=0.04$ )

- "Most movies and TV shows that show people smoking make it look more attractive than it really is." (total agreement: $83.7 \%$ vs. $90.6 \%$ respectively, $P<0.01$ )
Logistic regression models did not show a significant association between SML scores and smoking status (current vs. non-smokers): OR $0.82,95 \%$ CI $0.57-1.18, P=0.29$ in the unadjusted model; and OR 0.80, $95 \%$ CI $0.55-1.16, P=0.24$ in the adjusted model.

\section{DISCUSSION}

This study analyzed the attitudes towards smoking, knowledge about smoking, and the level of smoking media literacy among students of the largest and most prestigious medical school in Argentina. In contrast to what has happened in most highincome countries, where a decline in smoking prevalence among physicians preceded a decline in the general population, the smoking rate among medical students and recent graduates was similar to that in the general population. This high prevalence is particularly concerning considering that the potential positive impact of health professionals on public policies may be diminished by their own high smoking prevalence. We found that only half of participants agreed that doctors should act as an example to their patients, around one third thought that medical advice had little effect on patients' cessation behavior, and nearly $20 \%$ believed that physicians could decline care for patients who were smokers and failed to quit.

Current smokers were generally less likely to reveal an antismoking attitude when asked about physicians' role in tobacco 
Table 3 Level of Agreement with Banning Smoking in Public Places Among 1659 Current Students and Recent Graduates, by Smoking Status, University of Buenos Aires Medical School, Argentina, 2011

\begin{tabular}{llll}
\hline \hline Place & \multicolumn{3}{l}{ Agree with a full smoking ban } \\
\cline { 2 - 4 } & $\begin{array}{l}\text { Total } \\
(\boldsymbol{n}=\mathbf{1 6 5 9}) \\
\text { No. (\%) }\end{array}$ & $\begin{array}{l}\text { Current } \\
\text { smokers } \\
(\boldsymbol{n}=\mathbf{4 5 3}) \\
\text { No. (\%) }\end{array}$ & $\begin{array}{l}\text { Non-smokers } \\
(\boldsymbol{n}=\mathbf{1 2 0 6}) \\
\text { No. (\%) }\end{array}$ \\
& & $427(94.3)$ & $1185(98.3)$ \\
& $1612(97.2)$ & $426(94.0)$ & $1180(97.8)$ \\
Physicians' offices & $1606(96.8)$ & $422(93.2)$ & $1175(97.4)$ \\
Public transportation & $1597(96.3)$ & $410(90.5)$ & $1171(97.1)^{*}$ \\
Schools & $1581(95.3)$ & $342(75.5)$ & $1042(86.4)^{*}$ \\
Hospitals & $1384(83.4)$ & $338(74.6)$ & $1005(83.3)^{\dagger}$ \\
Universities & $1343(81.0)$ & $234(51.7)$ & $882(73.1)^{*}$ \\
Workplaces & $1116(67.3)$ & $206(45.5)$ & $824(68.3)^{*}$ \\
Restaurants & $1030(62.1)$ & $154(34.0)$ & $759(62.9)^{*}$ \\
Coffee shops & $913(55.0)$ & $158(34.9)$ & $739(61.3)^{*}$ \\
Nightclubs & $897(54.1)$ & 150 & \\
Bars &
\end{tabular}

Note: Totals may not add to $100 \%$ due to missing data

Non-smoker category includes never smokers and former smokers

Significant difference between current and non-smokers: $* P<0.001$; ${ }^{P} P=0.004$

control, especially with regard to being role models, while non-smokers and men were more likely to stigmatize patients who smoked and were unable to quit. Current medical students were less likely to correctly answer some of the knowledge questions and to recognize the importance of health professionals in helping patients to successfully quit smoking, which may be due to less clinical experience in observing the effects of tobacco use.

Our results were largely consistent with those found in other studies, in which medical students expressed a need for more training, and current smokers were less likely to have anti-smoking attitudes. ${ }^{15}, 19-21,33$ Even though most participants answered the knowledge-related questions correctly, most expressed a need for more training on tobacco cessation. Although a majority of respondents reflected an anti-smoking attitude, these results indicate that a significant number of medical students and young physicians do not believe that they have a greater responsibility in tobacco control just by virtue of being in a health-related profession.

Although indoor smoking bans have become widely accepted worldwide, including in Argentina, roughly one third to one half of respondents did not think that smoking should be fully banned in recreational venues such as cafes, which is similar to findings in other studies. ${ }^{20,21}$ This contradicts the fact that over $96 \%$ of respondents correctly disagreed that second-hand smoke is harmful only to young children, and implies that though most understand that second-hand smoking is harmful, exposure by consenting adults in recreational venues may be acceptable. Another possible explanation could be a belief that the rights of nonsmokers should not prevail in places where their presence is purely recreational and voluntary. This contrasted with more than 80-90 \% agreement among participants with a full smoking ban at work, health care and educational settings. Even though the reasons
Table 4 Odds of Agreeing with a Specific Attitude/Knowledge Statement or with a Full Smoking Ban Among 1659 Current Students and Recent Graduates, by Smoking Status and Student Status, University of Buenos Aires Medical School, Argentina, 2011

\begin{tabular}{|c|c|}
\hline $\begin{array}{l}\text { Analysis according to smoking status (non- } \\
\text { smokers as referent) }\end{array}$ & $\begin{array}{l}\text { Odds of agreement } \\
\text { (current smokers) }^{a}\end{array}$ \\
\hline Statement & OR $(95 \% \mathrm{CI})$ \\
\hline $\begin{array}{l}\text { The physician has a responsibility not to } \\
\text { smoke and set a good example for their } \\
\text { patients. }\end{array}$ & $0.39(0.31-0.48)^{b}$ \\
\hline $\begin{array}{l}\text { If a doctor wishes, he/she should be able to } \\
\text { refuse to care for a patient just because he } \\
\text { does not quit smoking. }\end{array}$ & $0.57(0.42-0.78)^{b}$ \\
\hline $\begin{array}{l}\text { The consumption of tobacco is a matter of } \\
\text { personal decision in which the doctor } \\
\text { should not intervene. }\end{array}$ & $1.46(1.004-2.11)^{\mathrm{c}}$ \\
\hline $\begin{array}{l}\text { Smoking on non-daily basis is not harmful } \\
\text { to health. }\end{array}$ & $1.77(1.16-2.71)^{\mathrm{d}}$ \\
\hline $\begin{array}{l}\text { Very light smoking ( } 1-5 \text { cigarettes per day) } \\
\text { is harmless to health. }\end{array}$ & $2.33(1.32-4.10)^{\mathrm{e}}$ \\
\hline \multicolumn{2}{|l|}{ Full smoking ban: } \\
\hline Hospitals & $0.30(0.16-0.58)^{\mathrm{b}}$ \\
\hline Universities & $0.55(0.41-0.73) \mathrm{b}$ \\
\hline Workplaces & $0.67(0.50-0.88)^{\mathrm{f}}$ \\
\hline Restaurants & $0.42(0.33-0.53)^{\mathrm{b}}$ \\
\hline Coffee shops & $0.41(0.33-0.51)^{\mathrm{b}}$ \\
\hline Nightclubs & $0.32(0.25-0.40)^{\mathrm{b}}$ \\
\hline Bars & $0.35(0.28-0.45)^{b}$ \\
\hline $\begin{array}{l}\text { Analysis according to student status } \\
\text { (current student as referent) }\end{array}$ & $\begin{array}{l}\text { Odds of agreement } \\
\text { (recent graduates) }\end{array}$ \\
\hline Statement & OR $(95 \% \mathrm{CI})$ \\
\hline $\begin{array}{l}\text { If a patient has smoked for a long time, it is } \\
\text { too late to stop, because their health is } \\
\text { already irreversibly affected. }\end{array}$ & $0.30(0.11-0.78)^{h}$ \\
\hline $\begin{array}{l}\text { Smoking on a non-daily basis is not } \\
\text { harmful to health. }\end{array}$ & $0.37(0.23-0.61)^{\mathrm{b}}$ \\
\hline $\begin{array}{l}\text { Regarding smoking cessation, medical } \\
\text { advice has little effect on the behavior of } \\
\text { patients. }\end{array}$ & $0.43(0.34-0.55)^{\mathrm{b}}$ \\
\hline $\begin{array}{l}\text { Patients already know they should quit } \\
\text { smoking. It doesn't make sense to remind } \\
\text { them of this. }\end{array}$ & $0.55(0.31-0.97)^{\mathrm{i}}$ \\
\hline $\begin{array}{l}\text { Of the patients who quit smoking, the } \\
\text { majority succeed in doing so on their first } \\
\text { attempt. }\end{array}$ & $0.72(0.54-0.94)^{\mathrm{j}}$ \\
\hline $\begin{array}{l}\text { It is doctors' responsibility to help their } \\
\text { patients quit smoking. }\end{array}$ & $1.57(1.14-2.17)^{\mathrm{k}}$ \\
\hline \multicolumn{2}{|l|}{ Full smoking ban: } \\
\hline Restaurants & $1.44(1.13-1.84)^{\mathrm{e}}$ \\
\hline Coffee shops & $1.33(1.05-1.67)^{\mathrm{j}}$ \\
\hline Bars & $1.31(1.05-1.64)^{1}$ \\
\hline
\end{tabular}

${ }^{a}$ Reference: non-smokers (never smokers + former smokers); ${ }^{g}$ Reference: current students

Models adjusted for age, gender, smoking status and student status Significance level indicated as follows: ${ }^{b} P<0.001 ; \quad{ }^{c} P=0.047$; ${ }^{d} P=0.008 ;{ }^{e} P=0.003 ;{ }^{f} P=0.004 ;{ }^{h} P=0.014 ;{ }^{i} P=0.037 ;{ }^{j} P=0.017$; ${ }^{k} P=0.006 ;{ }^{l} P=0.018$

for these observations deserve to be further explored, these findings do show a gap in knowledge among health professionals regarding the harm of second-hand smoke that needs to be addressed.

Our study did not find a significant difference in the level of smoking media literacy between current smokers and nonsmokers. This result is probably best explained by the fact that almost $90 \%$ of participants had high smoking media literacy, making it very difficult to find any difference between subgroups. The measure may also lose discriminatory power among older, more highly educated respondents such as medical students. Nevertheless, current smokers had a tendency to be less receptive to the notion that tobacco companies disguise 
certain messages, as shown in the individual items in which a difference was found.

There are limitations associated with this study. First, the lower response rate may affect the generalizability of the results, although this is consistent with other online surveys, ${ }^{51-54}$ and there was no obvious non-response bias, with gender distribution in our sample similar to that found in UBA. ${ }^{34}$ Second, the items about tobacco-related attitudes were not possible to use as a scale. Lastly, the crosssectional design of the study does not allow us to make any causal inference. Nevertheless, our study suggests that, while overall most medical students and recent medical graduates have strong anti-tobacco attitudes, a substantial proportion do not recognize the importance of their role as health professionals in tobacco control strategies. It is disappointing that even though the prevalence of tobacco use has decreased in Argentina, the rate among medical students has not declined at a faster pace. Considering that health professionals should be at the front line of anti-tobacco strategies, ${ }^{55-57}$ our findings imply that the opportunity to help smoking patients quit is probably being missed. Since most students reported a need for more training on smoking cessation treatment, increasing the time that UBA's medical school dedicates to tobacco control is desirable. An initial evaluation of the current curricular situation and a survey of the expectations of both students and faculty would guide the changes that are needed. Multimodal training strategies, including role-playing scenarios as well as seeing preceptors as positive role models, may also help in changing attitudes and teaching appropriate cessation treatments. ${ }^{26,58}$ Because physicians continue to be viewed with great respect by the Argentine public, their lack of awareness of this fact may partially explain the high smoking rate in this population, and may project them as negative role models. Medical schools not only need to implement changes in the medical curricula, but also need to develop cessation programs among their students.

\section{Acknowledgments:}

Contributors: We thank Professor Rodolfo Rothlin from the Universidad de Buenos Aires for assistance during data collection, Cecilia Populus-Eudave for administrative and research support, and Steven E. Gregorich, PhD, for advice on analytic approaches at UCSF.

Corresponding Author: Eliseo J. Pérez-Stable, MD; National Institute on Minority Health and Health DisparitiesNational Institutes of Health, Bethesda, MD, USA (e-mail: eliseo.perez-stable@nih.gov).

\section{Compliance with Ethical Standards:}

Funding: This research was funded by grant no.TW05935 from the Tobacco Research Network Program, Fogarty International Center, National Cancer Institute, National Institute of Drug Abuse, and National Institutes of Health.

Prior Presentations: An earlier version of the manuscript was presented as a poster at the 16th World Conference on Tobacco or Health in Abu Dhabi (United Arab Emirates) in March 2015, and at the 4th Latin American and Caribbean Conference on Tobacco or Health in Costa Rica in March 2014.
Conflict of Interest: The authors declare that they have no conflict of interest.

Disclaimer: The content of and views expressed in this manuscript are those of the authors and should not be construed to represent the views of the National Institutes of Health or any of the sponsoring organizations and agencies of the US government.

\section{REFERENCES}

1. Ferketich AK, Khan Y, Wewers ME. Are physicians asking about tobacco use and assisting with cessation? Results from the 2001-2004 National Ambulatory Medical Care Survey (NAMCS). Prev Med. 2006;43(6):472-6. doi:10.1016/j.ypmed.2006.07.009.

2. Eckert T, Junker C. Motivation for smoking cessation: what role do doctors play? Swiss Med Wkly. 2001;131(35-36):521-6.

3. Wallace PG, Brennan PJ, Haines AP. Are general practitioners doing enough to promote healthy lifestyle? Findings of the Medical Research Council's general practice research framework study on lifestyle and health. Br Med J (Clin Res Ed). 1987;294(6577):940-2. doi:10.1136/bmj.294.6577.940.

4. Patel MS, Steinberg MB. Smoking cessation. Ann Intern Med. 2016;164(5):Itc33-itc48. doi:10.7326/aitc201603010.

5. World Health Organization: Tobacco Free Initiative. Code of practice on tobacco control for health professional organizations Available at: http:// www.who.int/tobacco/wntd/2005/codeofpractice/en/index.html. Accessed 9/12/2016.

6. Caplan L, Stout C, Blumenthal DS. Training physicians to do office-based smoking cessation increases adherence to PHS guidelines. J Community Health. 2011;36(2):238-43. doi:10.1007/s10900-010-9303-0.

7. Cummings SR, Coates TJ, Richard RJ, et al. Training physicians in counseling about smoking cessation. A randomized trial of the "Quit for Life” program. Ann Intern Med. 1989;110(8):640-7. doi:10.7326/00034819-110-8-640.

8. Cummings SR, Richard RJ, Duncan CL, et al. Training physicians about smoking cessation: a controlled trial in private practice. J Gen Intern Med. 1989;4(6):482-9. doi:10.1007/BF02599545.

9. Mejia R, Perez-Stable EJ, Kaplan CP, et al. Effectiveness of an intervention to teach physicians how to assist patients to quit smoking in Argentina. Nicotine Tob Res. 2015. doi: 10.1093/ntr/ntv153.

10. Raupach T, Al-Harbi G, McNeill A, Bobak A, McEwen A. Smoking cessation education and training in U.K. medical schools: a national survey. Nicotine Tob Res. 2015;17(3):372-5. doi:10.1093/ntr/ntu199.

11. Makni H, O'Loughlin JL, Tremblay M, et al. Smoking prevention counseling practices of Montreal general practitioners. Arch Pediatr Adolesc Med. 2002;156(12):1263-7. doi:10.1001/archpedi.156.12.1263.

12. Pipe A, Sorensen M, Reid R. Physician smoking status, attitudes toward smoking, and cessation advice to patients: an international survey. Patient Educ Couns. 2009;74(1):118-23. doi:10.1016/j.pec.2008.07.042.

13. Meshefedjian GA, Gervais A, Tremblay M, Villeneuve D, O'Loughlin J. Physician smoking status may influence cessation counseling practices. Can J Public Health. 2010;101(4):290-3.

14. Vogt F, Hall S, Marteau TM. General practitioners' and family physicians' negative beliefs and attitudes towards discussing smoking cessation with patients: a systematic review. Addiction. 2005;100(10):1423-31. doi:10. 1111/j.1360-0443.2005.01221.x.

15. Grassi MC, Chiamulera C, Baraldo M, et al. Cigarette smoking knowledge and perceptions among students in four Italian medical schools. Nicotine Tob Res. 2012;14(9):1065-72. doi:10.1093/ntr/ntr330.

16. Romero MI, Santander J, Hitschfeld MJ, Labbé M, Zamora V. Consumo de tabaco y alcohol entre los estudiantes de medicina de la Pontificia Universidad Católica de Chile. Rev Med Chil. 2009;137(3):361-8. doi:10. 4067/S0034-98872009000300006.

17. Bian J, Du M, Liu Z, Fan Y, Eshita Y, Sun J. Prevalence of and factors associated with daily smoking among Inner Mongolia medical students in China: a cross-sectional questionnaire survey. Subst Abuse Treat Prev Policy. 2012;7:20. doi:10.1186/1747-597x-7-20.

18. Mehrotra R, Chaudhary AK, Pandya S, Mehrotra KA, Singh M. Tobacco use by Indian medical students and the need for comprehensive intervention strategies. Asian Pac J Cancer Prev. 2010;11(2):349-52.

19. Warren CW, Jones NR, Chauvin J, Peruga A. Tobacco use and cessation counselling: cross-country. Data from the Global Health Professions Student Survey (GHPSS), 2005-7. Tob Control. 2008;17(4):238-47. doi:10.1136/tc.2007.023895. 
20. Reynales-Shigematsu LM, Vázquez-Grameix JH, Lazcano-Ponce E. Encuesta Mundial de Tabaquismo en Estudiantes de la Salud, México 2006. Salud Publica Mex. 2007;49:s194-204.

21. Do YK, Bautista MA. Medical students' tobacco use and attitudes towards tobacco control. Med Educ. 2013;47(6):607-16. doi:10.1111/ medu. 12145.

22. Abdullah AS, Stillman FA, Yang L, Luo H, Zhang Z, Samet JM. Tobacco use and smoking cessation practices among physicians in developing countries: a literature review (1987-2010). Int J Environ Res Public Health. 2014;11(1):429-55. doi:10.3390/ijerph110100429.

23. Cattaruzza MS, West $\mathbf{R}$. Why do doctors and medical students smoke when they must know how harmful it is? Eur $\mathrm{J}$ Public Health 2013;23(2):188-9. doi:10.1093/eurpub/ckt001.

24. Smith DR, Leggat PA. An international review of tobacco smoking in the medical profession: 1974-2004. BMC Public Health. 2007;7:115. doi:10. 1186/1471-2458-7-115.

25. Smith DR, Leggat PA. An international review of tobacco smoking among medical students. J Postgrad Med. 2007;53(1):55-62. doi:10.4103/00223859.30333.

26. Hayes RB, Geller AC, Crawford SL, et al. Medical school curriculum characteristics associated with intentions and frequency of tobacco dependence treatment among 3rd year U.S. medical students. Prev Med. 2015;72:56-63. doi:10.1016/j.ypmed.2014.12.035

27. Lewis KE, Shin D, Davies G. Smoking habits and attitudes toward tobacco bans among United Kingdom hospital staff and students. Int J Tuberc Lung Dis. 2011;15(8):1122-6. doi:10.5588/ijtld.10.0783.

28. La Torre G, Kirch W, Bes-Rastrollo M, et al. Tobacco use among medical students in Europe: results of a multicentre study using the Global Health Professions Student Survey. Public Health. 2012;126(2):159-64. doi:10. 1016/j.puhe.2011.10.009.

29. Warren CW, Sinha DN, Lee J, Lea V, Jones NR. Tobacco use, exposure to secondhand smoke, and cessation counseling among medical students: cross-country data from the Global Health Professions Student Survey (GHPSS), 2005-2008. BMC Public Health. 2011;11:72. doi:10.1186/14712458-11-72.

30. Chen X, Tang $\mathbf{X}$, Stanton B, Li H, Chen w. Cigarette smoking among medical students in China and modifiable risk factors for smoking prevention. Health Educ. 2012;112(4):333-49. doi:10.1108/ 09654281211237162

31. Global Tobacco Surveillance System. Global Adult Tobacco Survey (GATS) 2012 Available at: http://www.paho.org/hq/index.php?option=com content\&view=article\&id=1751\%3Aglobal-adult-tobacco-survey gats $\&$ catid $=1278 \% 3$ Asde-surveillance-and-research\&lang=en. Accessed 9/12/2016.

32. Grupo FUMAr. Estudio F.U.M.Ar (Fumar en Universitarios de Medicina en Argentina) 2004: Ministerio de Salud de la Nacion; Available at: http:// www.msal.gov.ar/images/stories/bes/graficos/0000000020cnt-paperfumar-2004v4-CAEM_2005.pdf. Accessed 9/12/2016.

33. Konfino J, Mejia R, Ferrante D, Iermoli R, Perez Stable EJ. Efectos de un curso breve de tabaquismo en una facultad de medicina. Rev Argent Salud Pública. 2011;2(8):15-20.

34. Coordinación General de Planificación Estratégica e Institucional, Universidad de Buenos Aires. Censo de Estudiantes 2011 - Resultados Finales 2011 Available at: http://www.uba.ar/institucional/censos/ Estudiantes2011/estudiantes2011.pdf. Accessed 9/12/2016.

35. Fulmer EB, Neilands TB, Dube SR, Kuiper NM, Arrazola RA, Glantz SA. Protobacco media exposure and youth susceptibility to smoking cigarettes, cigarette experimentation, and current tobacco use among US youth. PLoS One. 2015;10(8), e0134734. doi:10.1371/journal.pone.0134734.

36. Charlesworth A, Glantz SA. Smoking in the movies increases adolescent smoking: a review. Pediatrics. 2005;116(6):1516-28. doi:10.1542/peds 2005-0141.

37. National Cancer Institute. The Role of the Media in Promoting and Reducing Tobacco Use. Bethesda, MD: U.S.: Department of Health and Human Services, National Institutes of Health, National Cancer Institute, 2008.

38. Thrasher JF, Sargent JD, Huang L, Arillo-Santillan E, Dorantes-Alonso A, Perez-Hernandez R. Does film smoking promote youth smoking in middle-income countries?: A longitudinal study among Mexican adolescents. Cancer Epidemiol Biomarkers Prev. 2009;18(12):3444-50. doi:10. 1158/1055-9965.epi-09-0883.
39. Morgenstern M, Sargent JD, Engels RC, Florek E, Hanewinkel R. Smoking in European adolescents: relation between media influences, family affluence, and migration background. Addict Behav. 2013;38(10):2589-95. doi:10.1016/j.addbeh.2013.06.008.

40. Morgenstern M, Sargent JD, Engels RC, et al. Smoking in movies and adolescent smoking initiation: longitudinal study in six European countries. Am J Prev Med. 2013;44(4):339-44. doi:10.1016/j.amepre. 2012.11.037.

41. Centers for Disease Control and Prevention. MediaSharp: Analyzing Tobacco and Alcohol Messages - Leader's Guide. Atlanta, Georgia: Centers for Disease Control and Prevention, Substance Abuse and Mental Health Services Administration, The American Academy of Pediatrics, National Education Association Health Information Network, 1998.

42. Primack BA, Gold MA, Land SR, Fine MJ. Association of cigarette smoking and media literacy about smoking among adolescents. J Adolesc Health. 2006;39(4):465-72. doi:10.1016/j.jadohealth.2006.05.011.

43. Primack BA, Sidani J, Carroll MV, Fine MJ. Associations between smoking and media literacy in college students. J Health Commun. 2009;14(6):541-55. doi:10.1080/10810730903089598.

44. Salgado Mv, Perez-Stable EJ, Primack BA, et al. Association of media literacy with cigarette smoking among youth in Jujuy, Argentina. Nicotine Tob Res. 2012;14(5):516-21. doi:10.1093/ntr/ntr240.

45. Salgado MV, Mejia R, Kaplan CP, Perez-Stable EJ. Smoking behavior and use of tobacco industry sponsored websites among medical students and young physicians in Argentina. J Med Internet Res. 2014;16(2), e35. doi:10.2196/jmir.2528.

46. DatStat. DatStat Illume Available at: http://www.datstat.com/datstatillume. Accessed 9/12/2016.

47. de Leon J, Diaz FJ, Becona E, Gurpegui M, Jurado D, Gonzalez-Pinto A. Exploring brief measures of nicotine dependence for epidemiological surveys. Addict Behav. 2003;28(8):1481-6. doi:10.1016/S0306-4603(02) 00264-2.

48. Perez-Rios M, Santiago-Perez MI, Alonso B, Malvar A, Hervada X, de Leon J. Fagerstrom test for nicotine dependence vs heavy smoking index in a general population survey. BMC Public Health. 2009;9:493. doi:10.1186/ 1471-2458-9-493.

49. Heatherton TF, Kozlowski LT, Frecker RC, Rickert W, Robinson J. Measuring the Heaviness of Smoking: using self-reported time to the first cigarette of the day and number of cigarettes smoked per day. Addiction. 1989;84(7):791-800. doi:10.1111/j.1360-0443.1989.tb03059.x.

50. Primack BA, Gold MA, Switzer GE, Hobbs R, Land SR, Fine MJ. Development and validation of a smoking media literacy scale for adolescents. Arch Pediatr Adolesc Med. 2006;160(4):369-74. doi:10. 1001/archpedi.160.4.369.

51. Nulty DD. The adequacy of response rates to online and paper surveys: what can be done? Assessment Eval High Educ. 2008;33(3):301-14 doi:10.1080/02602930701293231.

52. Hayslett MM, Wildemuth BM. Pixels or pencils? The relative effectiveness of Web-based versus paper surveys. Libr Inf Sci Res. 2004;26(1):73-93. doi:10.1016/j.lisr.2003.11.005.

53. Morrell HE, Cohen LM, Dempsey JP. Smoking prevalence and awareness among undergraduate and health care students. Am J Addict. 2008;17(3):181-6. doi:10.1080/10550490802019899.

54. Sinclair M, O'Toole J, Malawaraarachchi M, Leder K. Comparison of response rates and cost-effectiveness for a community-based survey: postal, internet and telephone modes with generic or personalised recruitment approaches. BMC Med Res Methodol. 2012;12(1):132. doi:10.1186/1471-2288-12-132

55. Tobacco Use and Dependence Guideline Panel. Treating Tobacco Use and Dependence: 2008 Update 2008 May. 3 Rockville (MD): US Department of Health and Human Services; Available at: http://www.ncbi.nlm.nih.gov/ books/NBK63948/. Accessed 9/12/2016.

56. World Health Organization, Tobacco Free Initiative. MPOWER Available at: http://www.who.int/tobacco/mpower/en/. Accessed 9/12/2016.

57. World Health Organization: Tobacco Free Initiative. Health systems and professionals Available at: http://www.who.int/tobacco/control/health professionals/en/indexl.html. Accessed 9/12/2016.

58. Ockene JK, Hayes RB, Churchill LC, et al. Teaching medical students to help patients quit smoking: outcomes of a 10-school randomized controlled trial. J Gen Intern Med. 2016;31(2):172-81. doi:10.1007/s11606-0153508-y. 